\title{
A model of milk production in lactating dairy cows in relation to energy and nitrogen dynamics
}

\author{
I. R. Johnson, ${ }^{*} \dagger^{1}$ J. France, $\dagger$ and B. R. Cullen* \\ ${ }^{*}$ Faculty of Veterinary \& Agricultural Sciences, University of Melbourne, Vic 3010, Australia \\ †Centre for Nutrition Modelling, Department of Animal \& Poultry Science, University of Guelph, Guelph, Ontario NIG 2W1, Canada
}

\begin{abstract}
A generic daily time-step model of a dairy cow, designed to be included in whole-system pasture simulation models, is described that includes growth, milk production, and lactation in relation to energy and nitrogen dynamics. It is a development of a previously described animal growth and metabolism model that describes animal body composition in terms of protein, water, and fat, and energy dynamics in relation to growth requirements, resynthesis of degraded protein, and animal activity. This is further developed to include lactation and fetal growth. Intake is calculated in relation to stage of lactation, pasture availability, supplementary feed, and feed quality. Energy costs associated with urine $\mathrm{N}$ excretion and methane fermentation are accounted for. Milk production and fetal growth are then calculated in relation to the overall energy and nitrogen dynamics. The general behavior of the model is consistent with expected characteristics. Simulations using the model as part of a whole-system pasture simulation model (DairyMod) are compared with experimental data where good agreement between pasture, concentrate and forage intake, as well as milk production over 3 consecutive lactation cycles, is observed. The model is shown to be well suited for inclusion in large-scale system simulation models.
\end{abstract}

Key words: dairy cow, model, lactation, energy dynamics

\section{INTRODUCTION}

Milk production in dairy cows has been modeled at various levels of complexity, from detailed biophysical processes to empirical lactation response curves. The widely used and detailed Californian model of the lactating dairy cow Molly (Baldwin et al., 1987a,b,c; Baldwin, 1995) has 2 main modules that describe ru-

Received July 5, 2015.

Accepted September 20, 2015.

${ }^{1}$ Corresponding author: ian@imj.com.au men processes and postabsorptive metabolism, providing insight into the metabolic processes fundamental to milk production. At a more fundamental level, individual models of rumen and mammary gland function can provide insight into the behavior of the underlying biochemical function relating to milk production (Neal and Thornley, 1983; Hanigan et al., 2001, 2002). At the other end of the spectrum, descriptive empirical curves are used to describe the lactation response following calving. These curves can be used for analysis of the time-course of milk production or for assessing feed requirement throughout the lactation cycle, although they contain little or no underlying mechanistic processes (Rook et al., 1993). Perhaps the most widely used lactation curve is the Wood equation (Wood, 1967), which uses the gamma function, although other equations are reviewed in Thornley and France (2007), which also provides a detailed discussion of dairy models in general.

A dairy farm typically represents a complex system with different interacting components. Generally, whole-farm approaches distinguish at least an animal component and a soil-crop component, and the models constructed are designed to give accurate representation of animal production, internal cycling of materials, and exchange between the farm and the environment (Schils et al., 2007b). Several whole-farm models exist to simulate milk production and related aspects such as grazing behavior and greenhouse gas emissions from dairy farms [e.g., DairyWise (Schils et al., 2007a), FarmGHG (Olesen et al., 2006), MINDY (Gregorini and Hanigan, 2012), and SIMS DAIRY (Del Prado and Scholefield, 2006)]. Proponents of these models demonstrate the ability to simulate a range of conditions and predict well. However, it is difficult to reproduce and verify their findings independently as concise mathematical descriptions are generally not readily accessible from mainstream literature.

Our focus is not only on milk production, but the interactions between the grazing animal and wholesystem dynamics, including pasture production and utilization, $\mathrm{N}$ dynamics, and system management. This 
requires a model that has appropriate mechanistic detail to describe the necessary biophysical processes, while being sufficiently tractable to allow inclusion in whole-system models. We describe an energy-driven model of lactation and $\mathrm{N}$ dynamics in dairy cows that includes both lactation and pregnancy. The model is an extension of the animal growth model of Johnson et al. (2012). It has been developed as an integral part of DairyMod (Johnson et al., 2008; Johnson, 2013), which is a biophysical whole-farm simulation model of dairy pasture systems incorporating pasture growth and utilization, water dynamics, soil organic matter and $\mathrm{N}$ dynamics, animal growth, and metabolism, as well as milk production. The model has flexible multipaddock management options, feeding regimens incorporating pasture, concentrate, forage, and TMR. The model, along with the SGS Pasture Model (Johnson et al., 2003), which is a livestock production model with the same underlying biophysical core, has been applied extensively in Australia and New Zealand, and other locations, to address a range of research questions such as the effects of climate variability, drought, business risk, and climate change on pasture production (e.g., Cullen et al., 2008). A primary objective in developing the model has been to ensure that each module has been constructed at a similar level of complexity, which allows us to explore the behavior of each component in the system and their interactions in a consistent manner. Although the model described here for milk production and $\mathrm{N}$ dynamics in dairy cows has been developed as an integral part of DairyMod, it will be suited to any whole-system dairy simulation model.

We first describe the model structure, with full mathematical description of the underlying processes, and then look at the general model behavior, including pregnancy, lactation, and $\mathrm{N}$ dynamics including partitioning between dung and urine to demonstrate the structural consistency in model behavior. This is followed by an analysis of a 3-yr period of a wholefarm dairy system that has been previously published (Chapman et al., 2014a,b; Hill et al., 2014; Tharmaraj et al., 2014).

\section{METHODS}

Animal Care and Use Committee approval was not obtained for this study because no animal experimentation was conducted.

\section{Model Overview}

The model is an extension of the animal growth model described by Johnson et al. (2012), which describes animal growth and energy dynamics in sheep and cattle in relation to available energy. Animal mass comprises protein $\left(W_{P}\right)$, water $\left(W_{H}\right)$, and fat $\left(W_{F}\right)$, with protein being the primary indicator of metabolic state, whereas fat is a potential source of energy for metabolic processes. Model variables are defined in Table 1, and parameters, with default values, are defined in Table 2. Parameter values will vary between different animal types and species, and our default values are the values we use for illustrations and analysis, unless we specifically mention otherwise. The total body weight is $W$, and all body components have units in kilograms, so that

$$
W=W_{P}+W_{H}+W_{F},
$$

Protein and water are assumed to be in fixed proportion, with

$$
W_{H}=\lambda W_{P},
$$

where $\lambda$ is a dimensionless constant with default value 3 . Thus, $W$ can be written

$$
W=(1+\lambda) W_{P}+W_{F} .
$$

The growth of protein is defined using a Gompertz equation in its derivative form, so that it defines growth rate, not actual BW (for a discussion, see Thornley and France, 2007), with actual protein growth dependent on protein mass and available energy. Fat growth is secondary and depends on the current protein mass and is constrained to a maximum potential fat fraction of total BW. Protein degradation occurs so that energy is required for protein resynthesis (that is, the maintenance of existing protein). Energy is also required for activity, which, combined with that for protein resynthesis, defines the total maintenance energy requirement. This approach to defining energy required for activity is also assumed to include any significant costs associated with thermoregulation. A normal fat proportion is defined, which increases during growth. If the energy is not sufficient for protein and fat growth, after accounting for maintenance, then fat growth will be reduced. Conversely, if the energy available exceeds maintenance and normal protein and fat growth requirements, then excess growth occurs solely in the fat component. The model was demonstrated to give realistic growth dynamics for animal BW and components under a range of available energy conditions (Johnson et al., 2012).

Central to the model structure is the relationship between available energy and growth of body compo- 
Table 1. Model variables, definitions, and units ${ }^{1}$

\begin{tabular}{|c|c|c|}
\hline Variable & Definition & Unit $^{2}$ \\
\hline $\begin{array}{l}E_{D} \\
E_{U, N} \\
E_{M, \text { avail }} \\
I \\
I_{N} \\
I_{\text {pot, ref }} \\
I_{\text {pot,ref,preg }}\end{array}$ & $\begin{array}{l}\text { Energy costs of dung production } \\
\text { Energy costs of urine production, related to urine } \mathrm{N} \\
\text { Energy available for milk production } \\
\text { Total daily intake } \\
\text { Total daily } \mathrm{N} \text { intake } \\
\text { Potential intake as a function of body protein at reference digestibility } \\
\text { Potential intake as a function of body protein at reference digestibility during } \\
\text { pregnancy }\end{array}$ & $\begin{array}{l}\mathrm{MJ} \mathrm{d}^{-1} \\
\mathrm{MJ} \mathrm{d}^{-1} \\
\mathrm{MJ} \mathrm{d} \\
\mathrm{kg} \text { of d.wt d } \\
\mathrm{kg} \text { of } \mathrm{N} \mathrm{d}^{-1} \\
\mathrm{~kg} \text { of d.wt d } \\
\mathrm{kg} \text { of d.wt d }\end{array}$ \\
\hline $\begin{array}{l}W \\
W_{P}, W_{H}, W_{F} \\
W_{f} \\
W_{f, 0} \\
W_{b} \\
W_{b, n_{f}}\end{array}$ & $\begin{array}{l}\text { Empty body weight } \\
\text { Protein, water, fat components of } \mathrm{W} \\
\text { Fetus weight } \\
\text { Initial value for fetus weight } \\
\text { Birth weight } \\
\text { Birth weight for } n_{f} \text { fetuses }\end{array}$ & $\begin{array}{l}\mathrm{kg} \\
\mathrm{kg} \\
\mathrm{kg} \\
\mathrm{kg} \\
\mathrm{kg} \\
\mathrm{kg}\end{array}$ \\
\hline $\begin{array}{l}f_{I, \text { preg }} \\
f_{I, \text { lact }} \\
f_{N D F, \text { feed }}, f_{P, \text { feed }}, f_{S, \text { feed }}\end{array}$ & $\begin{array}{l}\text { Scale function for intake potential during pregnancy } \\
\text { Scale function for intake potential during lactation } \\
\text { NDF (fiber), protein, and neutral detergent solubles (sugars and so on) composition of } \\
\text { intake }\end{array}$ & \\
\hline$\phi_{\delta}$ & Scale function for effect of pasture availability on intake & \\
\hline$\phi_{F, \text { lact }}$ & Fat catabolism function growth during lactation priority function & \\
\hline$\psi$ & Apparent ME coefficient & $\mathrm{MJ} \mathrm{d}^{-1}$ \\
\hline
\end{tabular}

${ }^{1}$ Body composition components are protein, water, and fat. Energy dynamics include requirements for pregnancy and lactation. Intake can include pasture and supplementary feed. Symbols are ordered alphabetically: uppercase and then lowercase, English and then Greek.

${ }^{2}$ d.wt $=$ dry weight.

nents. If the energy content of body tissue is $\varepsilon$ (MJ $\mathrm{kg}^{-1}$ ) and the efficiency of growth is $Y$, then the energy required per unit growth, $E\left(\mathrm{MJ} \mathrm{kg}^{-1}\right)$, is

$$
E=\frac{\varepsilon}{Y}
$$

This equation is applied to protein and fat components, with subscripts $P$ and $F$.
The present model extends that described by Johnson et al. (2012) to include pregnancy and lactation as well as $\mathrm{N}$ dynamics, including partitioning of $\mathrm{N}$ between dung and urine.

\section{Pregnancy}

Fetal growth is assumed to be exponential (NRC, 2001, 2007; CSIRO, 2007) so that the growth rate is 
Table 2. Model parameters and values used in the simulations presented here ${ }^{1}$

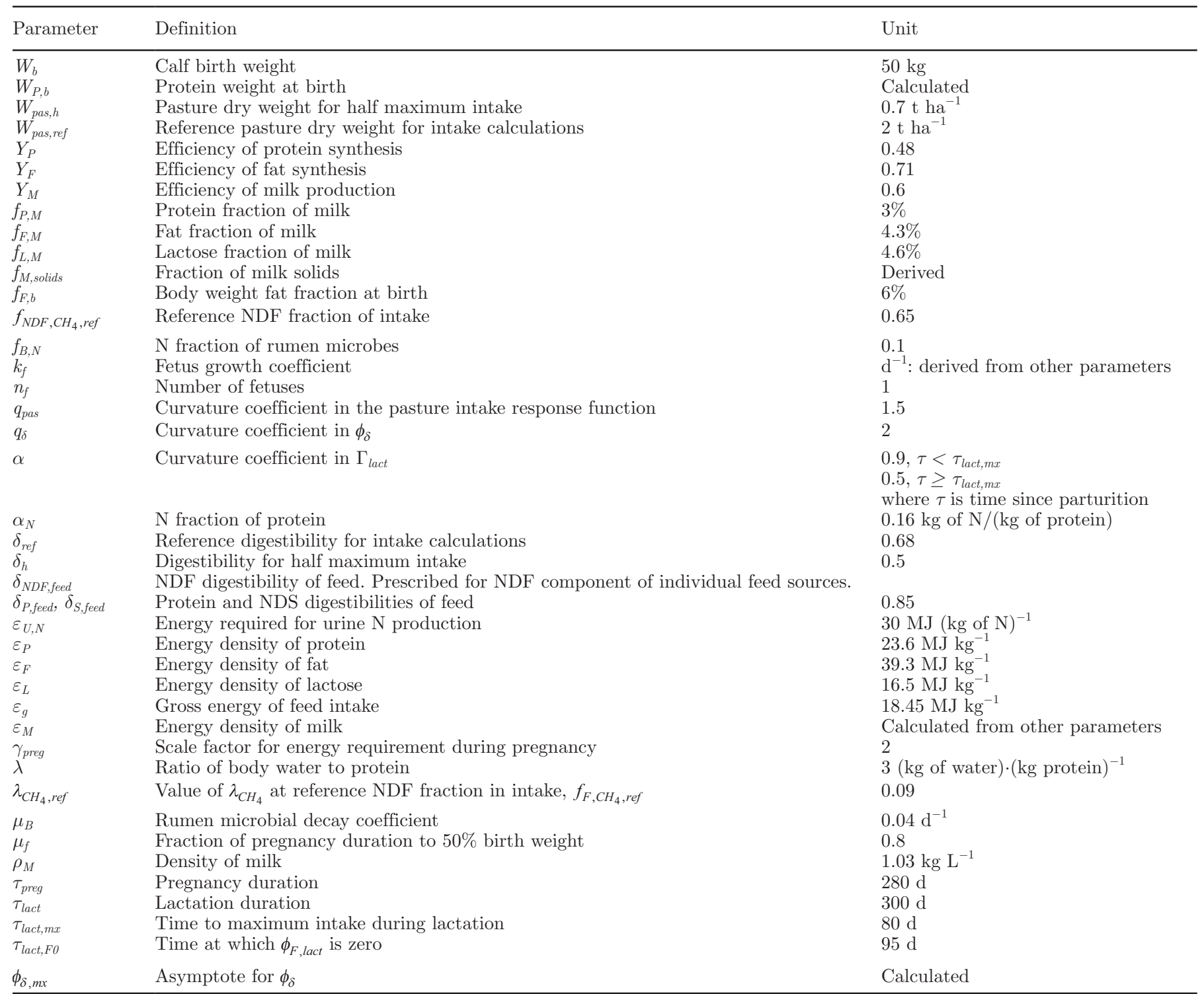

${ }^{1}$ Symbols are ordered alphabetically, uppercase and then lowercase, English and then Greek. The parameters will vary for different animal breeds.

$$
\frac{\mathrm{d} W_{f}}{\mathrm{~d} t}=k_{f} W_{f}
$$

where $W_{f}(\mathrm{~kg})$ is the fetus weight, and $k_{f}\left(\mathrm{~d}^{-1}\right)$ is a growth coefficient. For normal growth, this equation is solved to give

$$
W_{f}=W_{f, 0} e^{k_{f} t}
$$

Denoting pregnancy duration by $\tau_{\text {preg }}$ and the birth weight by $W_{b}$, it follows that

$$
W_{f, 0}=W_{b} e^{-k_{f} t_{\text {preg }}} .
$$

Rather than specifying the growth coefficient $k_{f}$, it is convenient to prescribe the fraction of pregnancy duration to $50 \%$ birth weight, denoted by $\mu_{f}$, so that

$$
W_{f}\left(t=\mu_{f} t_{\text {preg }}\right)=W_{b} / 2,
$$

which, with equation [6], gives 


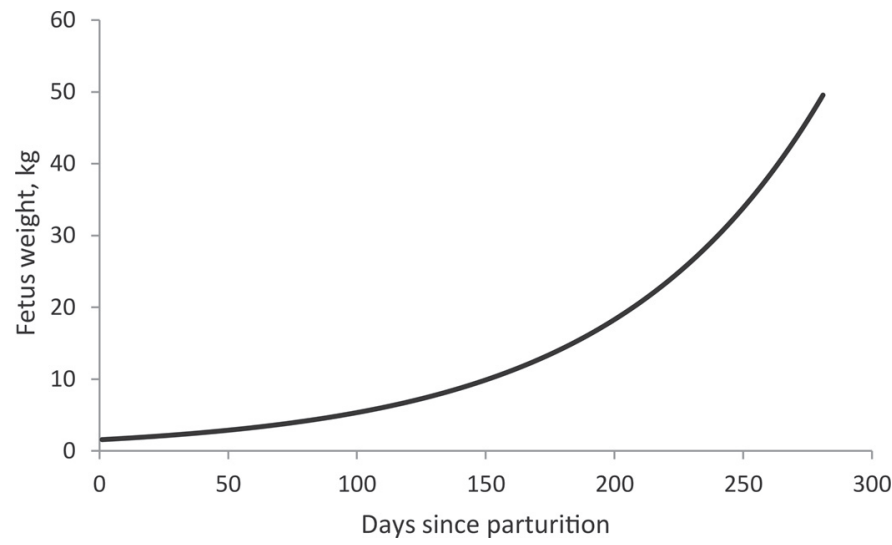

Figure 1. Fetal growth in dairy cows with default parameters.

$$
k_{f}=\frac{\ln (2)}{\tau_{\text {preg }}\left(1-\mu_{f}\right)}=\frac{0.69}{\tau_{\text {preg }}\left(1-\mu_{f}\right)} .
$$

Fetal growth parameters to be defined are $W_{b}, \tau_{\text {preg }}, \mu_{f}$, with defaults

$$
W_{b}=50 \mathrm{~kg}, \tau_{\text {preg }}=280 \mathrm{~d}, \mu_{f}=0.8 .
$$

Equation [6] with [7] and [9] defines fetal growth in relation to birth weight, pregnancy duration, and the time to $50 \%$ birth weight. $W_{f}$ is illustrated in Figure 1. It can be seen that, at conception, fetal weight does not increase smoothly from zero-the model could be refined to make this the case but the effect on simulations would be negligible and would not justify the extra complexity.

When multiple fetuses are present, $n_{f}$, birth weight is reduced and it is assumed that

$$
W_{b, n_{f}}=\left(\frac{2}{1+n_{f}}\right) W_{b} \text {. }
$$

It can be seen that the total fetal weight has been considered and not the individual protein, fat, and water components, which has been done to avoid undue complexity. It is well established that the net energy requirements for pregnancy in ruminants are directly related to the size and number of fetuses due to gravid uterus composition (ARC, 1980; AFRC, 1998; NRC, 2001, 2007). To calculate energy requirement during pregnancy, it is assumed that fat and protein composition during fetal growth is constant and the same as at birth. Thus, applying equation [4] to the fat and protein components of fetal BW, the energy required for fetal growth, $E_{\text {preg,req }}\left(\mathrm{MJ} \mathrm{d}^{-1}\right)$, is

$$
E_{\text {preg,req }}=\left(f_{F, b} \frac{\varepsilon_{F}}{Y_{F}}+\frac{W_{P, b}}{W_{b}} \frac{\varepsilon_{P}}{Y_{P}}\right) \gamma_{\text {preg }} n_{f},
$$

where $f_{F, b}$ is the body fat fraction at birth, $W_{P, b}$ is the protein mass at birth as calculated from equation [3], $\varepsilon_{F}$ and $\varepsilon_{P}$ are the energy densities of fat and protein (MJ $\mathrm{kg}^{-1}$ ), and $\gamma_{\text {preg }}$ (with default value 2 ) is a scale factor to allow for the fact that the energy required during pregnancy is greater than that for fetal growth alone (Rattray et al., 1974).

\section{Lactation}

We now turn attention to the energy dynamics of lactation. Milk production can be defined either as liters per day or kilograms of milk solids per day. Denoting the fat, protein, and lactose fractions of milk as $f_{F, M}$, $f_{P, M}, f_{L, M}$, respectively, and the density of milk as $\rho_{M}$, the fraction of milk solids, $f_{M \text {,solids }}\left(\mathrm{kg}\right.$ of solids $\left.\mathrm{L}^{-1}\right)$, is

$$
f_{M, \text { solids }}=\rho_{M}\left(f_{F, M}+f_{P, M}\right)
$$

and the energy density of milk, $\varepsilon_{M}\left(\mathrm{MJ} \mathrm{L}^{-1}\right)$, is

$$
\varepsilon_{M}=\rho_{M}\left(\varepsilon_{F} f_{F, M}+\varepsilon_{P} f_{P, M}+\varepsilon_{L} f_{L, M}\right),
$$

where the energy densities for fat and protein were defined earlier, and $\varepsilon_{L}$ is the energy density of lactose (Table 2).

Applying equation [4], the energy required for milk production can now be written

$$
E_{M}=\frac{\varepsilon_{M}}{Y_{M}} \mathrm{MJ} \cdot \mathrm{L}^{-1}
$$

Fat Catabolism During Lactation. Although fat catabolism can occur at any time during animal growth if energy intake is sufficiently restricted, during lactation additional fat catabolism occurs, particularly during early lactation, to provide the extra energy requirements associated with the production of milk. As time progresses, a shift occurs from priority for milk production, which incurs fat catabolism, to replacing body fat through fat growth. This is defined in the model through the scale function

$$
\phi_{F, \text { lact }}(\tau)=\frac{\tau-\tau_{\text {lact }, F_{0}}}{\tau+\tau_{\text {lact }, F_{0}}}
$$

where $\tau$ is the time $(\mathrm{d})$ since parturition. $\phi_{F, \text { lact }}$ lies between \pm 1 as $\tau_{\text {lact }}$ increases from zero, taking the value 
0 when $\tau_{\text {lact }}=\tau_{\text {lact }, F_{0}}$, and the default value is $\tau_{\text {lact }, F_{0}}=$ 95 d. Equation [16] is illustrated in Figure 2.

When this function is negative, compulsory fat catabolism occurs, and when it is positive it defines the relative priority for fat growth and milk production. The overall growth dynamics are discussed later.

\section{Animal Intake}

The model of Johnson et al. (2012) did not include feed intake directly but defined growth and metabolism in relation to available intake energy. For the present purposes, we need to define intake in relation to feed availability and quality because, during lactation, intake potential is assumed to increase. Also, feed composition affects $\mathrm{N}$ dynamics through the animal as well as milk production.

It is common for models to relate potential intake to animal BW in some way. The approach here is to assume that, for a reference digestibility, normal growth can be satisfied with nonlimiting feed availability. Potential intake at this digestibility is then related to animal body protein, rather than total weight, because, as discussed above, body protein is taken as the primary indicator of metabolic state. Thus, for example, if a mature animal loses body fat but not protein, the potential intake is unchanged.

The approach when solving the equations is to grow an animal under normal conditions and calculate the ME required, which is then stored in an array as a function of body protein, $W_{P}$. The corresponding intake at reference digestibility, $\delta_{\text {ref }}$, that provides this ME is defined by

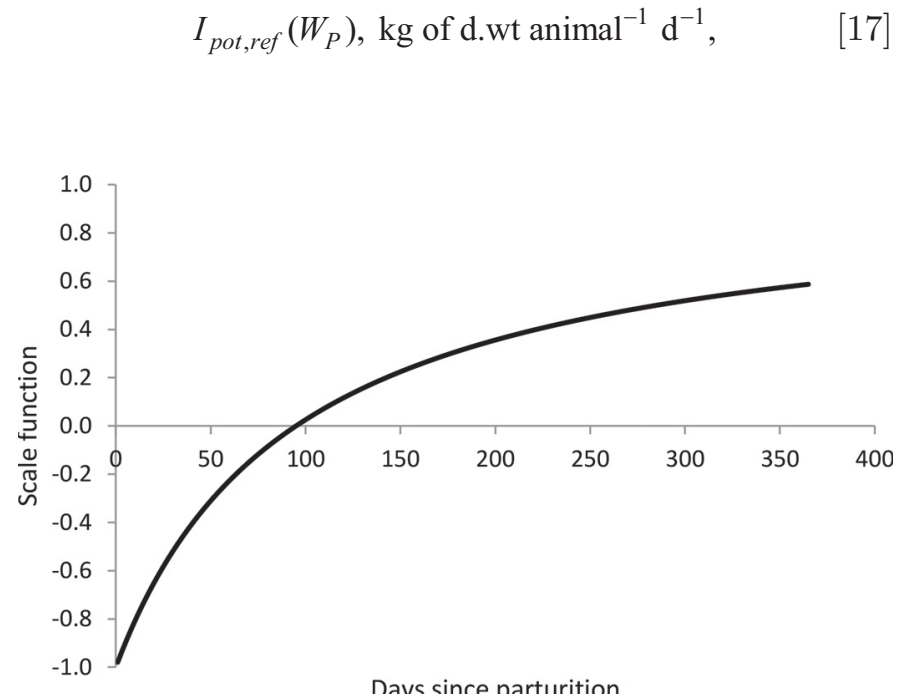

Figure 2. Scale function, equation [16], for fat catabolism and partitioning between fat growth and milk production for a dairy cow. where d.wt $=$ dry weight. This is then evaluated and applied at all stages of growth.

During pregnancy or lactation, it is assumed that potential intake increases due to physiological changes in the rumen. These are considered in turn.

Intake During Pregnancy. Potential intake is assumed to increase during pregnancy to provide the extra energy required for fetal growth. The simple scale function, assumed to increase linearly as energy requirements increase, is

$$
f_{I, \text { preg }}\left(t_{\text {preg }}\right)=1+\frac{E_{\text {preg }, \text { req }}}{E_{\text {mat }, \text { req }}},
$$

where $t_{\text {preg }}(\mathrm{d})$ is the time since conception, $E_{\text {preg,req }}$ (MJ $\mathrm{d}^{-1}$ ) is the energy required for pregnancy as given by equation [12], and $E_{\text {mat,req }}\left(\mathrm{MJ} \mathrm{d}^{-1}\right)$ is the energy required for a nonpregnant, nonlactating animal at normal mature weight. Combining equations [17] and [18], the potential intake during pregnancy is

$$
I_{\text {pot,ref,preg }}=I_{\text {pot,ref }}\left(W_{P}\right) f_{I, \text { preg }}\left(t_{\text {preg }}\right) .
$$

Intake During Lactation. Potential intake is assumed to increase to a peak following parturition and subsequently decline, according to the function

$$
f_{I, \text { lact }}\left(t_{\text {lact }}\right)=1+\left(f_{I, \text { lact }, m x}-1\right) \Gamma\left(t_{\text {lact }}\right),
$$

where $\Gamma\left(t_{\text {lact }}\right)$ is defined as a normalized gamma functions in terms of the time since parturition, $t_{\text {lact }}(\mathrm{d})$, time to maximum intake, $\tau_{\text {lact, } m x}(\mathrm{~d})$, and the curvature coefficient $\alpha$, as given by

$$
\Gamma\left(t_{\text {lact }}\right)=\left(\frac{t_{\text {lact }}}{\tau_{\text {lact }, m x}}\right)^{\alpha} \exp \left[-\alpha\left(\frac{t_{\text {lact }}}{\tau_{\text {lact }, m x}}-1\right)\right] \text {, }
$$

where

$$
\begin{aligned}
& \Gamma\left(t_{\text {lact }}=0\right)=0 \\
& \Gamma\left(t_{\text {lact }}=\tau_{\text {lact }, m x}\right)=1
\end{aligned}
$$

so that

$$
\begin{aligned}
& f_{I, \text { lact }}\left(t_{\text {lact }}=0\right)=1 \\
& f_{I, \text { lact }}\left(t_{\text {lact }}=\tau_{\text {lact }, m x}\right)=f_{I, \text { lact }, m x} .
\end{aligned}
$$

It should be noted that, in the model, different curvature parameter values for $\alpha$ can be used for pre- and post-peak lactation. 
During lactation, the potential intake function in equation [17] is scaled according to

$$
I_{p o t, \text { ref,lact }}=I_{\text {pot, ref }}\left(W_{P}\right) \Gamma\left(t_{\text {lact }}\right) .
$$

Default parameter values are

$$
\begin{aligned}
& \tau_{\text {lact }, m x}=80 \mathrm{~d} ; \alpha=0.9, t<\tau_{\text {lact }, m x}, \\
& \alpha=0.5, t \geq \tau_{\text {lact }, m x} ; f_{\text {I,lact }, m x}=2.2,
\end{aligned}
$$

although these values will vary between different breeds.

Intake in Relation to Composition and Feed Availability. The analysis so far has considered potential intake for feed at a reference digestibility, and we now briefly consider how actual intake is affected by availability and composition.

Animal feed, whether from pasture or supplement, is assumed to comprise 3 basic components: NDF, which is primarily cellulose, hemicellulose, and lignin in cell wall material; protein; and the remainder, which is the neutral detergent solubles and is mainly sugars for pasture but may include compounds such as starch and fat for other feeds. The fractions of these are denoted by $f_{N D F, f e e d}, f_{P, \text { feed }}, f_{S, \text { feed }}$, respectively, which sum to unity. If these components have digestibilities $\delta_{N D F, f e e d}, \delta_{P, \text { feed }}$, $\delta_{S, f e e d}$, respectively, then the total digestibility is

$$
\delta_{\text {feed }}=\delta_{N D F, \text { feed }} f_{N D F, \text { feed }}+\delta_{P, \text { feed }} f_{P, \text { feed }}+\delta_{S, \text { feed }} f_{S, \text { feed }} .
$$

In the present analysis, we assumed that

$$
\delta_{P, \text { feed }}=\delta_{S, \text { feed }}=0.85 \text {, }
$$

although this can easily be relaxed. Thus, variation in digestibility of different feed types is influenced primarily by composition and the digestibility of the NDF component.

A dimensionless digestibility intake scale factor, $\phi_{\delta}$, introduced to describe the influence of digestibility on potential intake, is defined as

$$
\phi_{\delta}=\phi_{\delta, m x}\left(\frac{\left(\delta_{\text {feed }} / \delta_{h}\right)^{q_{\delta}}}{1+\left(\delta_{\text {feed }} / \delta_{h}\right)^{q_{\delta}}}\right) \text {, }
$$

where

$$
\phi_{\delta, m x}=\frac{1+\left(\delta_{r e f} / \delta_{h}\right)^{q_{\delta}}}{\left(\delta_{r e f} / \delta_{h}\right)^{q_{\delta}}} .
$$
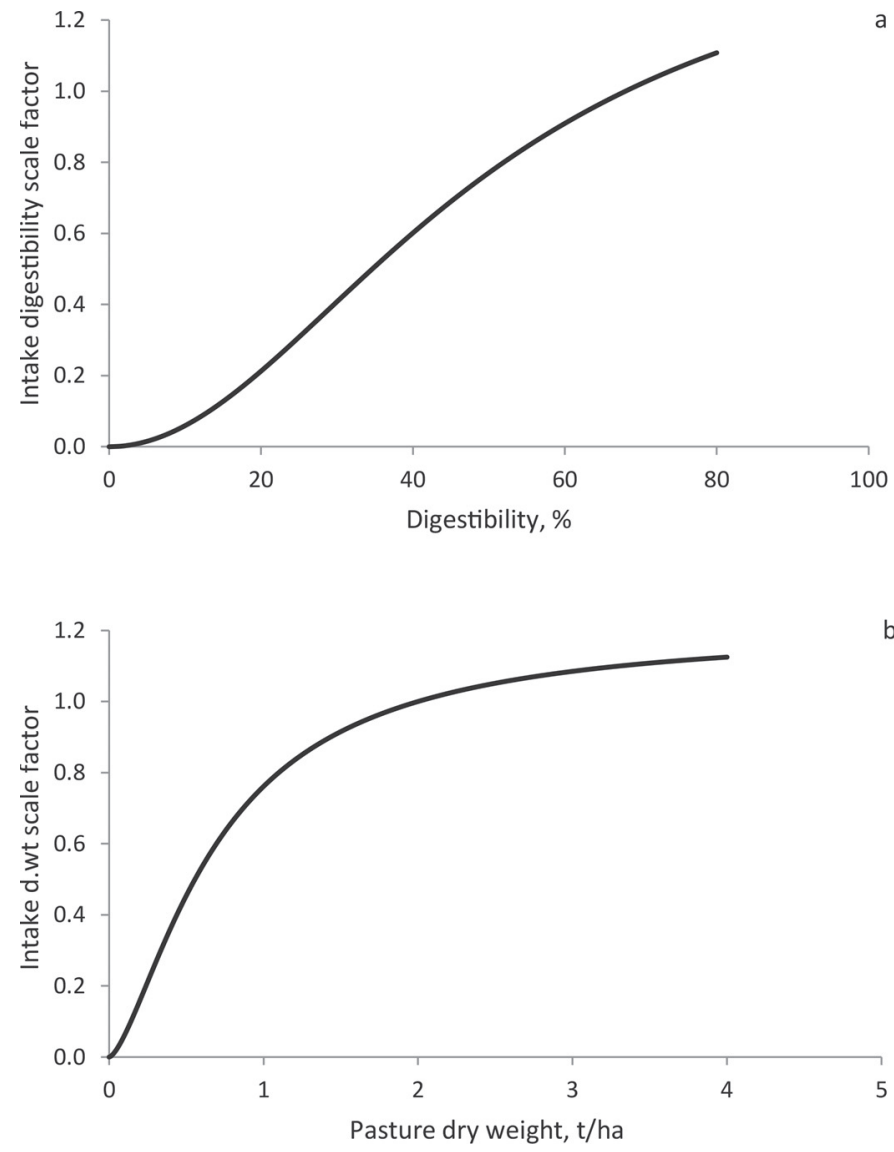

Figure 3. Scale factors for intake in relation to feed digestibility (a) and pasture availability (b). d.wt $=$ dry weight.

According to these equations, $\phi_{\delta}$ increases from zero when digestibility is zero, takes the values 0.5 and 1 at digestibilities $\delta_{h}$ and $\delta_{\text {ref }}$, respectively, and has asymptote $\phi_{\delta, m x}$ as given by equation [29]. The coefficient $q_{\delta}$ affects the curvature of the equation. The response, which is based on the general switch type equation discussed by Thornley and Johnson (2000, chapter 2), is illustrated in Figure 3a for default parameter values

$$
\delta_{h}=0.5, \delta_{\text {ref }}=0.68, q_{\delta}=2 .
$$

It is simple to adjust the shape of the curve by varying these 3 parameters. Note that, because this function is defined to take the value unity at reference digestibility 0.68 , it will exceed unity at digestibilities above that value.

Pasture intake depends on pasture mass as well as quality. A generic scale factor is defined to define intake in relation to available pasture, which is defined in a mathematically equivalent way to that for $\phi_{\delta}$ above (equations [28], [29]), with default parameter values 


$$
W_{\text {pas }, h}=0.7 \mathrm{t} \cdot \mathrm{ha}^{-1}, W_{\text {pas }, \text { ref }}=2 \mathrm{t} \cdot \mathrm{ha}^{-1}, q_{\text {pas }}=1.5, \quad[31]
$$

where $W_{p a s}$ refers to pasture d.wt. Again, it is simple to adjust the shape of this curve, which is illustrated in Figure $3 b$.

Supplement intake is related to supplement composition and digestibility, as well as any management restrictions in supply. Potential intake is defined in a similar way to pasture intake, but at the asymptote where intake is not restricted by availability.

\section{Metabolizable Energy and Nitrogen Dynamics}

The theory so far describes the diet composition and digestibility, which determine potential animal intake, and we now consider ME in relation to feed composition and $\mathrm{N}$ dynamics, which are central to overall nutrient dynamics in the model. Nitrogen dynamics are considered first because energy costs are associated with urine excretion and these affect overall available $\mathrm{ME}$. The net $\mathrm{N}$ balance through the animal is simple in that the input is equal to the sum of $\mathrm{N}$ retained (body tissue or milk) and that excreted in dung and urine. In the case of a nonlactating cow maintaining a fixed BW, excreted $\mathrm{N}$ will exactly balance input. However, the animal requires dietary $\mathrm{N}$ to balance turnover of rumen microbes. It is beyond the scope of the present model to include full rumen functionality, although such models provide valuable insight into rumen dynamics. A simpler approach is adopted.

Denoting the total intake by $I\left(\mathrm{~kg}\right.$ of d.wt $\left.\mathrm{d}^{-1}\right)$, the corresponding $\mathrm{N}$ intake is

$$
I_{N}=\alpha_{N} f_{P, \text { feed }} I
$$

where $f_{P, f e e d}$ is the protein fraction, and $\alpha_{N}$ is the $\mathrm{N}$ fraction of protein, taken to be $0.16 \mathrm{~kg}$ of $\mathrm{N}$ ( $\mathrm{kg}$ of protein $)^{-1}$, which is equivalent to the usual factor of 6.25 for converting $\mathrm{N}$ to protein.

Rumen microbe activity is not addressed directly, but some account has to be made of $\mathrm{N}$ losses through microbial senescence. It is assumed that this senescence and subsequent excretion of rumen microbes is exactly balanced by new growth. It is further assumed that rumen microbial senescence, $B_{\text {sen }}\left(\mathrm{kg}\right.$ of d.wt $\left.\mathrm{d}^{-1}\right)$, is proportional to intake, which implies that as microbial activity increases through greater intake, so does the turnover of microbes. Thus,

$$
B_{\text {sen }}=\mu_{B} I
$$

where $\mu_{B}\left(\mathrm{~d}^{-1}\right)$ is a microbial decay coefficient. The corresponding $\mathrm{N}$ excretion from rumen microbes is then

$$
B_{\text {sen }, N}=f_{B, N} B_{\text {sen }},
$$

where $f_{B, N}\left[\mathrm{~kg}\right.$ of $\left.\mathrm{N}(\mathrm{kg} \text { of } \mathrm{d} . \mathrm{wt})^{-1}\right]$ is the $\mathrm{N}$ fraction of the rumen microbes with default value 0.1 . If no account is made for microbial decay then for a mature, nongrowing, animal, the only source of excreted $\mathrm{N}$ is through undigested protein. Allowing for microbial decay ensures consistent $\mathrm{N}$ concentration in dung (see below).

Now consider dung, $D\left(\mathrm{~kg}\right.$ of d.wt d $\left.\mathrm{d}^{-1}\right)$, which is given by

$$
D=\left(1-\delta_{\text {feed }}\right) I+B_{\text {sen }}=\left(1-\delta_{\text {feed }}\right) I+\mu_{B} I,
$$

and the corresponding dung $\mathrm{N}, D_{N}\left(\mathrm{~kg}\right.$ of $\left.\mathrm{N} \mathrm{d}^{-1}\right)$, is

$$
\begin{aligned}
D_{N} & =\alpha_{N} f_{P, \text { feed }} I\left(1-\delta_{P, \text { feed }}\right)+B_{\text {sen }, N} \\
& =\alpha_{N} f_{P, \text { feed }} I\left(1-\delta_{P, \text { feed }}\right)+\mu_{B} f_{B, N} I .
\end{aligned}
$$

The $\mathrm{N}$ fraction of dung can now be written as

$$
f_{N, \text { dung }}=\frac{\alpha_{N} f_{P, \text { feed }}\left(1-\delta_{P, \text { feed }}\right)+\mu_{B} f_{B, N}}{\left(1-\delta_{\text {feed }}+\mu_{B}\right)} .
$$

The default value of $\mu_{B}$ is $0.04 \mathrm{~d}^{-1}$ so that microbial decay is equivalent to $4 \%$ of intake. Thus, for example, for a good quality pasture with digestibility $75 \%$, and $25 \%$ protein, the dung $\mathrm{N}$ concentration is $3.4 \%$, which is consistent with observation (Eckard et al., 2007).

Urine $\mathrm{N}$ is taken to be the excess intake $\mathrm{N}$ that is not used by the animal or excreted as dung. The total daily $\mathrm{N}$ input balance between intake, retained and losses to dung and urine is

$$
I_{N}=\Delta W_{N}+M_{N}+D_{N}+U_{N},
$$

where $\Delta W_{N}$ is the body weight $\mathrm{N}$ balance (and is negative for protein weight loss), $M_{N}$ is the $\mathrm{N}$ content of milk (where appropriate), and $U_{N}$ is the $\mathrm{N}$ loss as urine: all terms have units of kilograms of $\mathrm{N}$ per day. Thus, $U_{N}$ becomes

$$
U_{N}=I\left(\alpha_{N} f_{P, \text { feed }} \delta_{P, \text { feed }}-\mu_{B} f_{B, N}\right)-M_{N}-\Delta W_{N} .
$$

This gives the urine $\mathrm{N}$ balance in terms of intake, $\mathrm{N}$ retained by microbial biomass, milk, and BW change. 
For example, if the animal is not lactating and has no weight change, then all digested $\mathrm{N}$ that is not retained by the microbes is excreted as $\mathrm{N}$. The $\mathrm{N}$ retained by the microbes is balanced by the corresponding losses to dung through microbial senescence.

The ME available to the animal, $E_{M E}\left(\mathrm{MJ} \mathrm{d}^{-1}\right)$, is the difference between the gross energy of feed intake and energy costs associated with the production of methane and urine $\mathrm{N}$, and can be written as

$$
E_{M E}=\varepsilon_{g} \delta I-E_{C H_{4}}-E_{U, N},
$$

where $\varepsilon_{q}\left(\mathrm{MJ} \mathrm{kg}^{-1}\right)$ is the energy density of the feed, with default value $18.45 \mathrm{MJ} \mathrm{kg}^{-1}$ (IPCC, 2006), and the last 2 terms are energy costs associated with $\mathrm{CH}_{4}$ production through rumen fermentation and urine $\mathrm{N}$ excretion, respectively. They are considered in turn.

Energy costs associated with $\mathrm{CH}_{4}$ production are assumed to be given by

$$
E_{\mathrm{CH}_{4}}=\lambda_{\mathrm{CH}_{4}} \varepsilon_{g} \delta I,
$$

where $\lambda_{\mathrm{CH}_{4}}$ is a dimensionless variable defining the proportion of digestible energy intake that is lost as methane. $\lambda_{\mathrm{CH}_{4}}$ is related to the fiber fraction of the diet, $f_{N D F}$, according to

$$
\lambda_{\mathrm{CH}_{4}}=\lambda_{\mathrm{CH}_{4}, \mathrm{ref}}\left(\frac{f_{\mathrm{NDF}, \text { feed }}}{f_{\mathrm{NDF}, \mathrm{CH}, \mathrm{ref}}}\right)^{1 / 2},
$$

and $\lambda_{\mathrm{CH}_{4} \text {,ref }}$ is the value of $\lambda_{\mathrm{CH}_{4}}$ at the reference fiber fraction $f_{\mathrm{NDF}, \mathrm{CH}_{4}, \mathrm{ref}}$. Default values are

$$
\lambda_{\mathrm{CH}_{4}, \mathrm{ref}}=0.09 ; f_{\mathrm{NDF}, \mathrm{CH}_{4}, \mathrm{ref}}=0.65 \text {. }
$$

Thus, for example, if $\delta_{N D F, \text { feed }}=0.6, \delta_{P, \text { feed }}=\delta_{S, \text { feed }}=0.85$, then for composition $f_{N D F, \text { feed }}=0.55, f_{P, \text { feed }}=0.2, f_{S, \text { feed }}=$ 0.25 , which is representative of pasture, the fraction of gross energy intake lost through methane fermentation is $6.1 \%$, whereas if the composition is now $f_{N D F, f e e d}=$ $0.2, f_{P, \text { feed }}=0.1, f_{S \text {,feed }}=0.7$, which is representative of a concentrate supplement, the energy fraction is now $4.2 \%$. These values are consistent with lower energy costs through methane fermentation for low-fiber diets (Beauchemin et al., 2009).

The energy costs associated with urine are related to the urine $\mathrm{N}$, so that

$$
E_{U, N}=\varepsilon_{U, N} U_{N},
$$

where the urine output, $U_{N}$, is given by equation [39] and $\varepsilon_{U, N}$ is the energy cost of producing urine $\mathrm{N}$, with default value of $30 \mathrm{MJ}(\mathrm{kg} \text { of } \mathrm{N})^{-1}(\mathrm{NRC}, 2001)$.

It is convenient to separate urine $\mathrm{N}$ into the component corresponding to no $\mathrm{N}$ retention by the animal and then allow for any retention as milk or BW change. To do so, write equation [39] as

$$
U_{N}=U_{N, 0}-\Delta N_{\text {ret }},
$$

where

$$
U_{N, 0}=I\left(\alpha_{N} f_{P, \text { feed }} \delta_{P, \text { feed }}-\mu_{B} f_{B, N}\right)
$$

is the urine $\mathrm{N}$ that would be excreted in the absence of any retention by the animal, including lactation, and the $\mathrm{N}$ retained by the animal, $\Delta_{N r e t}$, corresponds to the $\mathrm{N}$ in milk plus any change in body weight $\mathrm{N}$, as given by

$$
\Delta N_{\text {ret }}=M_{N}+\Delta W_{N}
$$

The ME, equation [40], can now be written as

$$
E_{M E}=\psi I+\varepsilon_{U, N} \Delta N_{r e t},
$$

where

$$
\psi=\varepsilon_{g} \delta_{\text {feed }}\left(1-\lambda_{C H_{4}}\right)-\varepsilon_{U, N}\left(\alpha_{N} f_{P, \text { feed }} \delta_{P, \text { feed }}-f_{B, N} \mu_{B}\right) .
$$

This coefficient $\left(\mathrm{MJ} \mathrm{kg}{ }^{-1}\right.$ ) is termed the apparent ME coefficient and is the ME content of the feed in the absence of any $\mathrm{N}$ retention by the animal. It therefore follows that the actual ME available to the animal is not a function of the feed composition alone, but also the $\mathrm{N}$ dynamics in the animal so that, for example, if the same feed is supplied to nongrowing animals that are either lactating or not lactating, the ME content available to the lactating animal will be greater due to the $\mathrm{N}$ retention in milk. This difference is due to the costs of excreting surplus $\mathrm{N}$ in urine.

\section{Growth, Milk Production, and Fetal Growth in Response to Metabolizable Energy}

The analysis so far defines the ME available to the animal in terms of available pasture and quality, supplement supplied, and animal metabolic state. It now remains to calculate the overall growth dynam- 
ics including milk production and fetal growth where appropriate. The sequence of calculations using the theory described above is as follows:

- Calculate potential intake from pasture and supplement.

- Calculate ME required for growth, maintenance, and if relevant, pregnancy.

- If the animal is lactating and $\tau<\tau_{\text {lact, } F_{0}}$ in equation [16], so that fat catabolism occurs, calculate the energy released.

It then remains to calculate growth. First, consider a nonlactating animal, in which case, 3 conditions are considered:

- ME available exceeds requirements for growth, maintenance, and pregnancy (if appropriate). In this case, intake is reduced to maximum requirement and growth is calculated accordingly.

- ME available is less than requirements for growth, but fat catabolism is sufficient to meet maintenance requirements. In this case, no growth occurs and the necessary fat catabolism occurs to provide energy, along with intake, to meet maintenance requirements.

- ME available through intake and fat catabolism is insufficient to meet maintenance requirements. This is an animal that is going to lose weight and does so first through maximum fat catabolism. Body protein will then be lost as a result of insufficient energy to resynthesize degraded protein through protein maintenance requirements.

For a lactating animal, lactation will only occur if the energy available exceeds maintenance requirements. If this is the case and the available energy after meeting other costs is $E_{\text {lact,avail }}$ and daily milk production is $M(\mathrm{~L}$ $\mathrm{d}^{-1}$ ), then the energy balance is

$$
L\left(\frac{\varepsilon_{M}}{Y_{M}}-f_{N, M} \varepsilon_{U, N}\right)=E_{\text {lact,avail }},
$$

where $f_{N, M}\left(\mathrm{~kg}\right.$ of $\left.\mathrm{N} \mathrm{L}^{-1}\right)$ is the milk $\mathrm{N}$ fraction. This equation accounts for the energy that is available through $\mathrm{N}$ retention in the milk that would otherwise have incurred a cost to be excreted as urine. Thus, the milk production is

$$
M=\frac{E_{\text {lact,avail }}}{\left(\frac{\varepsilon_{M}}{Y_{M}}-f_{N, M} \varepsilon_{U, N}\right)} .
$$

In practice in the model, milk production will respond to pasture availability and quality as well as feed management.

\section{RESULTS AND DISCUSSION}

As discussed earlier, the model described here is the lactating cow component of DairyMod (Johnson et al., 2008; Johnson, 2013), and the focus on developing the model has been to provide a versatile description of milk production in dairy cows that can be incorporated in whole-farm simulation models for dairy systems. We shall first present illustrations of the model behavior under simplified conditions and then as part of a wholefarm analysis.

\section{General Model Dynamics}

In practice in DairyMod, milk production responds to pasture availability and quality as well as feed management. However, as a simple example, consider a dairy cow being fed 2 contrasting feeds:

- a fixed good-quality, pasture-based feed with $50 \%$ NDF at $60 \%$ digestibility, and $20 \%$ protein. The model parameters are given in Table 2 .

- a mixed ration feed with $25 \%$ NDF at $80 \%$ digestibility, and $20 \%$ protein.

In both cases protein and neutral detergent solubles have a digestibility of $85 \%$. The corresponding lactation over $300 \mathrm{~d}$ is shown in Figure 4 where it can be seen that, as expected, substantially greater milk production occurs with the mixed ration, with total milk production being 7,329 and 9,924 L, respectively. These examples show 2 extremes, and in practice, cows are likely to receive a balance between pasture, concentrate, forage, and mixed ration. However, this example demonstrates the model gives the appropriate response to differing feed supply. It should be noted that the absolute values for milk production will depend on the definition of model parameters that can be adjusted to reflect size and genetic merit of the cow.

Body weight and energy dynamics corresponding to the pasture-fed cow in Figure 4 are shown in Figure 5. The characteristics of the dynamics are similar for the mixed ration feed supply. It can be seen that BW declines following parturition as expected through fat catabolism and this weight is regained as the lactation cycle progresses. The negative growth energy corresponds to this fat catabolism. Also, no net protein weight loss occurs, although this may not be the case for animals with poor feed supply. A small step increase 


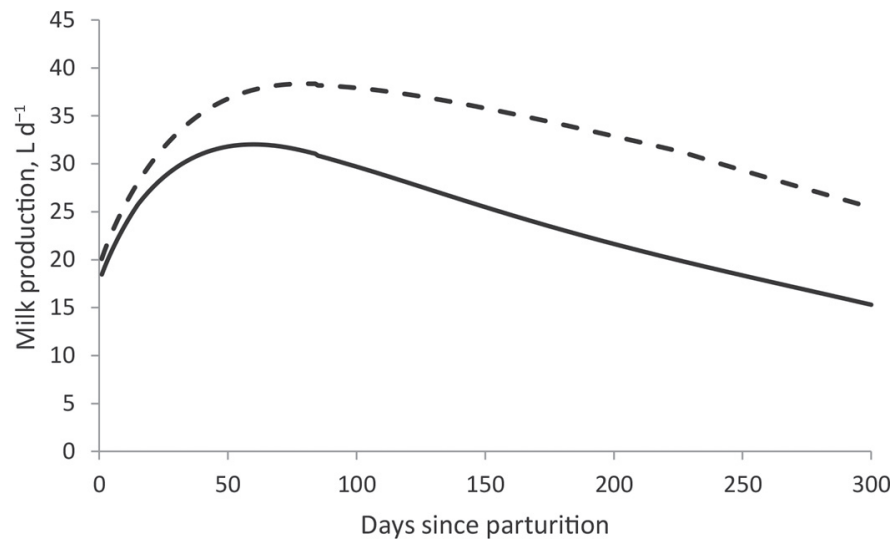

Figure 4. Milk production over $300 \mathrm{~d}$ of lactation for a cow being fed good quality pasture (solid line) or mixed ration feed (broken line).

in growth energy can be seen when lactation ceases, which is due to the greater energy available for growth processes.

\section{Application in a Whole-Farm Simulation}

To demonstrate model capacity in pasture-based dairy production systems, we used DairyMod to simulate cow feed intake and milk production and compared the results with experimental data from the Project 3030 "Ryegrass Max" farmlet in southwest Victoria, Australia. This was a whole-farm study looking at milk production, pasture, forage, and concentrate intake. The objective of this analysis is to show that the model of animal growth and lactation described here can be incorporated into a large-scale pasture system simulation model and that the results display the expected characteristics of the system. The Project 3030 farmlet design and management (Chapman et al., 2014b) and experimental results for pasture production (Tharmaraj et al., 2014), feed intake, and milk production (Chapman et al., 2014a; Hill et al., 2014) have been previously reported. Briefly the farmlet experiment was conducted with a herd of 36 Holstein Friesian cows grazing on 16.4 ha (stocking rate of 2.2 cows $\mathrm{ha}^{-1}$ ). The site at Terang, Victoria, Australia, has a temperate climate with mean annual rainfall of $785 \mathrm{~mm}$ (1,901 to 2,013 inclusive). Pasture was the main source of feed offered to cows, but they were also fed grain every day during milking, and hay or silage when pasture availability was limited (generally in summer and autumn, occasionally in winter). Cows calved in winter and were milked for approximately $300 \mathrm{~d}$ per lactation. Cows were milked twice per day. Further specific details of the experiment are reported in the articles cited above.

The climate, soil, pasture, feed management, and cow parameters from the experiment where used to simu- late the dairy production system in DairyMod. Daily climate data were obtained from the SILO PatchPoint data set (Jeffrey et al., 2001). The soil type was a brown chromosol, and perennial ryegrass (Lolium perenne) was the dominant pasture species (Chapman et al., 2014b). Rotational grazing through the 20 paddocks was implement in the model by targeting grazing to occur at 2.5 $\mathrm{t}$ of $\mathrm{DM} \mathrm{ha} \mathrm{h}^{-1}$ and removing stock at an average residual pasture mass of $1.5 \mathrm{t}$ of $\mathrm{DM} \mathrm{ha}{ }^{-1}$, in line with the practice in the experiment. Pasture production for this, and other, locations with the model has been tested and reported previously (Cullen et al., 2008). Cow feed intake was predicted by the model according to pasture availability and rules for minimum and maximum grain and hay/silage feeding, which varied according to stage of lactation. Calving date was simulated as June 15, and results analyzed from July, in line with the time when the whole herd was lactating in the experiment, to the end of February at which time all cows in the herd were still lactating. The cow parameters used for the simulation are those listed in Table 2.
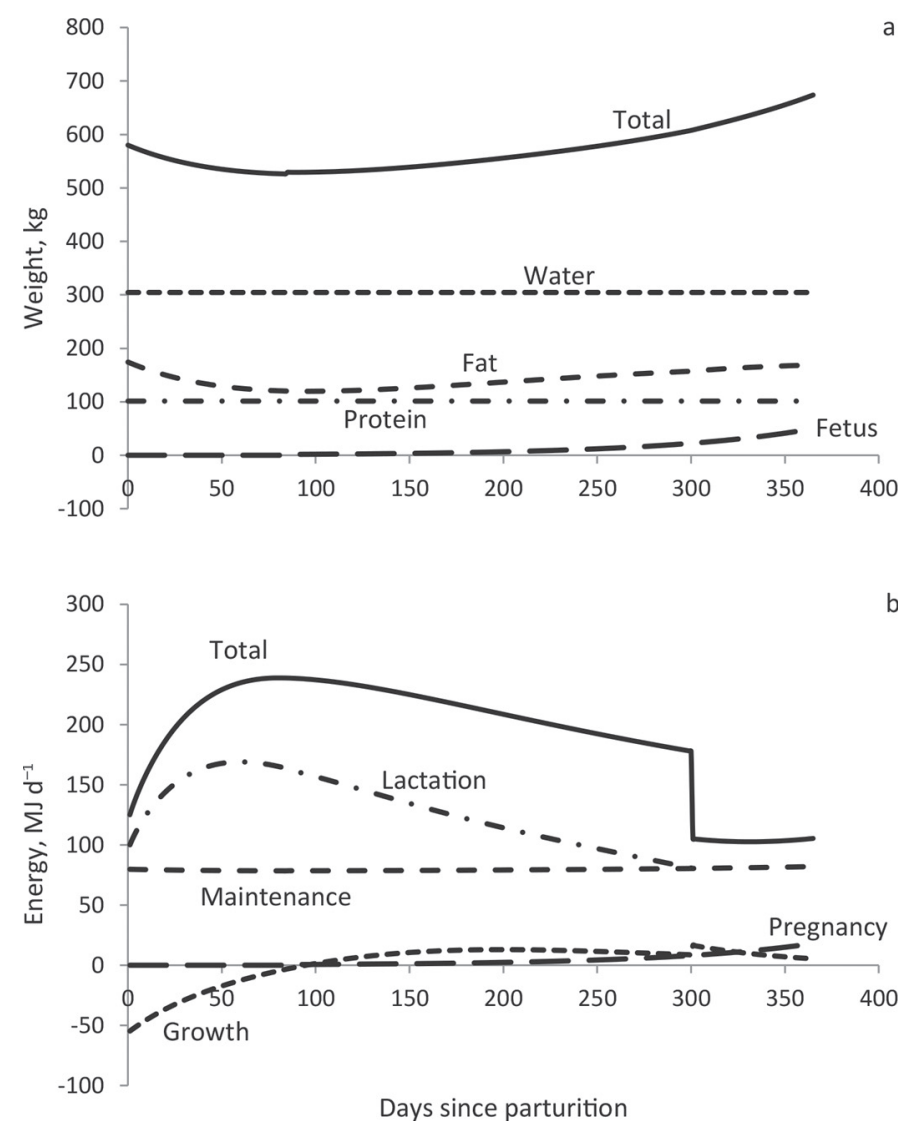

Figure 5. Body weight (a) and energy dynamics (b) for the pasture-fed dairy cow as illustrated in Figure 4. The BW and energy components are indicated. 


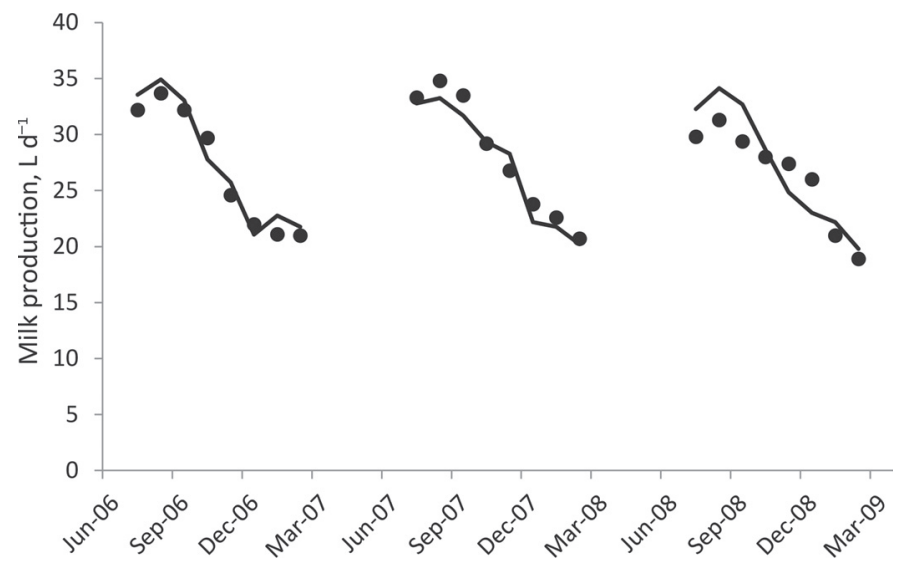

Figure 6. Average daily lactation, calculated monthly, for the Terang simulation for 3 lactations (July 2006 to March 2009). The lines are simulations, and the solid circles are observed data.

The monthly experiment data were compared with simulation results for 3 lactations (July 2006 to March 2009). Monthly average milk production (expressed per day) is illustrated in Figure 6, and it can be seen that the model and data are in good agreement. Pasture intake is illustrated in Figure 7 and supplement in Figure 8. The model simulated well both the expected feed intake patterns within years. Statistical analysis is presented in Table 3 for comparison between simulated and observed values, where $\mathrm{R}^{2}$, bias correction factor, and concordance correlation coefficient are shown. These values demonstrate, respectively, that the model gives a good description of the data, there is good agreement on the 1:1 line, and relatively little bias on the 1:1 line. The main discrepancy between the model and data occurred with forage intake in the

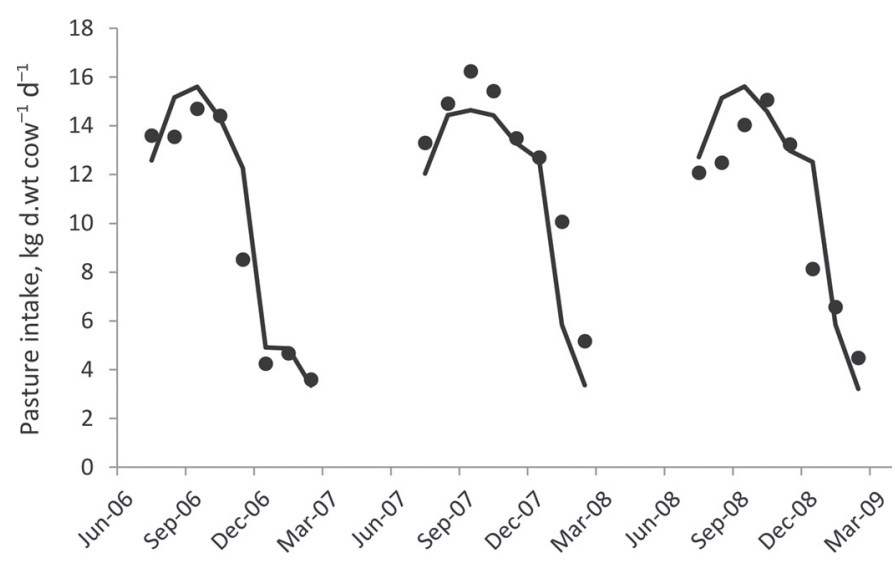

Figure 7. Average daily pasture intake for the Terang simulation corresponding to Figure 6. The lines are simulations, and the solid circles are observed data. d.wt $=$ dry weight.

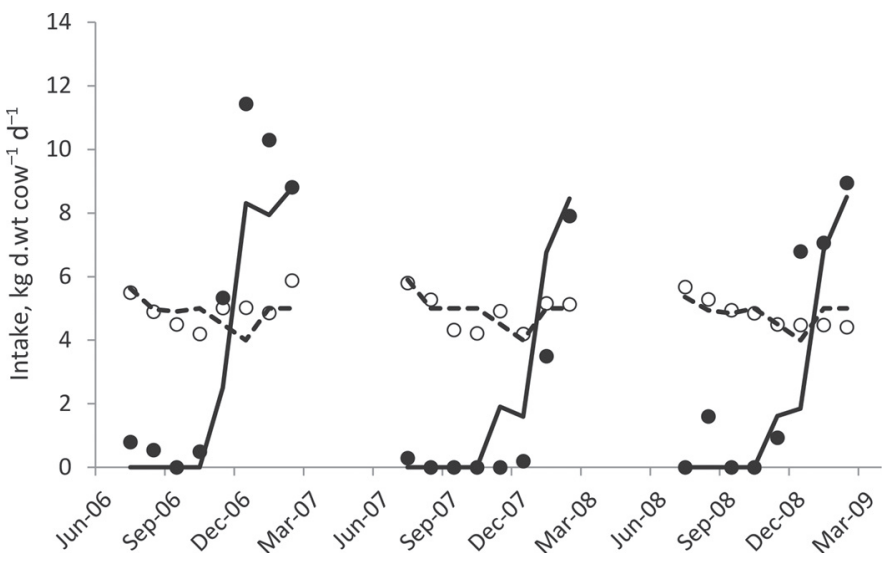

Figure 8. Average daily supplement intake for the Terang simulation corresponding to Figure 6. Solid lines are simulated forage, solid symbols are observed forage, broken lines are simulated concentrate, open symbols are observed concentrate. d.wt $=$ dry weight.

summer of the first lactation. This was at least in part due to the lower ME content of forage fed in the late spring and early summer period (Hill et al., 2014), and possibly due to increased wastage when high rates of forage were fed. The characteristics of the model simulations and data are consistent; in particular, high rates of pasture intake in spring being replaced in the diet by silage in the summer and differences between years. For example, pasture intake is lower in the first spring (from November 2006) than the following 2 springs, and this was due to the low spring rainfall in 2006 that resulted in reduced pasture growth and, consequently, greater forage feeding during this time compared with the following $2 \mathrm{yr}$. The pattern of milk production is also consistent with the observed data.

Although the consistency between the model and observed data is an important test of this type of model, for complex systems it is rare that complete data sets are available to test the entire model as discussed, for example, by Oreskes et al. (1994), Thornley and Johnson (2000), Thornley and France (2007), and so it is important to look at the underlying model behavior. The simulations comparing model behavior with experimental data, combined with those showing the general dynamics of the model, give confidence in the overall robustness of the model.

\section{CONCLUSIONS}

In this paper, we describe a dairy cow simulation model, which includes energy dynamics for fat and protein synthesis, energy released from fat catabolism, pregnancy and lactation, as well as nitrogen dynamics, and have presented a complete mathematical statement 
Table 3. Statistical analysis of the simulated and observed data for milk production, and pasture, forage, and concentrate intake as illustrated in Figures 6,7 , and $8^{1}$

\begin{tabular}{lcccc}
\hline Item & $\begin{array}{c}\text { Milk } \\
\left(\mathrm{L} \mathrm{d}^{-1}\right)\end{array}$ & $\begin{array}{c}\text { Pasture intake } \\
\left(\mathrm{kg} \mathrm{d}^{-1}\right)\end{array}$ & $\begin{array}{c}\text { Forage intake } \\
\left(\mathrm{kg} \mathrm{d}^{-1}\right)\end{array}$ & $\begin{array}{c}\text { Concentrate intake } \\
\left(\mathrm{kg} \mathrm{d}^{-1}\right)\end{array}$ \\
\hline $\mathrm{R}^{2}$ & 0.88 & 0.83 & 0.86 & 0.96 \\
$\mathrm{CCC}$ & 0.94 & 0.91 & 0.92 & 0.94 \\
$\mathrm{BCF}$ & 1.00 & 0.99 & 1.00 & 0.96 \\
\hline
\end{tabular}

${ }^{1} \mathrm{R}^{2}$ gives an indication of the overall agreement between the model and data; concordance correlation coefficient (CCC) is a measure of agreement to the 1:1 line; bias correction factor (BCF) is an indication of bias on the 1:1 line.

of the model. It is an intake-driven model with the balance between the individual animal processes being dependent on total metabolizable energy available to the animal. The model is constructed from relatively simple assumptions and includes the important underlying physiological processes. The simulations presented here demonstrate that the model is suitable for a range of applications in whole-system dairy simulation models.

\section{ACKNOWLEDGMENTS}

We are grateful for funding from to Dairy Australia (Melbourne) through the Dairy Businesses for Future Climates project. We also thank the Canada Research Chairs program (National Science and Engineering Council, Ottawa) for funding.

\section{REFERENCES}

AFRC. 1998. The Nutrition of Goats. CAB Int., New York, NY.

ARC. 1980. The Nutrient Requirements of Ruminant Livestock. Commonwealth Agricultural Bureaux, Slough, UK.

Baldwin, R. L. 1995. Modeling Ruminant Digestion and Metabolism. Chapman \& Hall, London.

Baldwin, R. L., J. France, D. E. Beever, M. Gill, and J. H. M. Thornley. 1987c. Metabolism of the lactating dairy cow. 3. Properties of mechanistic models suitable for evaluation of energetic relationships and factors involved in the partition of nutrients. J. Dairy Res. 54:133-145.

Baldwin, R. L., J. France, and M. Gill. 1987a. Metabolism of the lactating cow: 1. Animal elements of a mechanistic model. J. Dairy Res. 54:77-105.

Baldwin, R. L., J. H. M. Thornley, and D. E. Beever. 1987b. Metabolism of the lactating cow: 2. Digestive elements of a mechanistic model. J. Dairy Res. 54:107-131.

Beauchemin, K. A., T. A. McAllister, and S. M. McGinn. 2009. Dietary mitigation of enteric methane from cattle. CAB Reviews: Perspectives in Agriculture, Veterinary Science, Nutrition and Natural Resources 4, No. 035.

Chapman, D. F., D. Beca, J. Hill, J. Tharmaraj, J. L. Jacobs, and B. R. Cullen. 2014a. Increasing home-grown forage consumption and profit in non-irrigated dairy systems. 4. Economic performance. Anim. Prod. Sci. 54:256-262.

Chapman, D. F., J. Hill, J. Tharmaraj, D. Beca, S. N. Kenny, and J. L. Jacobs. 2014b. Increasing home-grown forage consumption and profit in non-irrigated dairy systems. 1. Rationale, systems design and management. Anim. Prod. Sci. 54:221-233.

CSIRO. 2007. Nutrient Requirements of Domesticated Ruminants. M. Freer, H. Dove, and J. V. Nolan, ed. CSIRO Publ., Melbourne, Australia.
Cullen, B. R., R. J. Eckard, M. N. Callow, I. R. Johnson, D. F. Chapman, R. P. Rawnsley, S. C. Garcia, T. White, and V. O. Snow. 2008. Simulating pasture growth rates in Australian and New Zealand grazing systems. Aust. J. Agric. Res. 59:761-768.

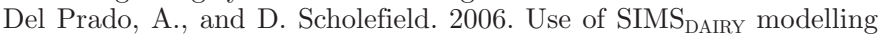
framework system to specify sustainable UK dairy farms. Delivering sustainability within profitable farming systems - Is it possible? Asp. Appl. Biol. 80:73-80.

Eckard, R. J., D. F. Chapman, and R. E. White. 2007. Nitrogen balances in temperate perennial grass and clover dairy pastures in south-eastern Australia. Aust. J. Agric. Res. 58:1167-1173.

Gregorini, P., and M. D. Hanigan. 2012. A mechanistic dynamic model to simulate diurnal patterns of herbage intake, grazing behaviour and nutrient supply of a dairy cow, MINDY: Brief description. Can. J. Anim. Sci. 92:557-559.

Hanigan, M. D., L. A. Crompton, B. J. Bequette, J. A. N. Mills, and J. France. 2002. Modelling mammary metabolism in the dairy cow to predict milk constituent yield, with emphasis on amino acid metabolism and milk protein production: Model evaluation. J. Theor. Biol. 217:311-330.

Hanigan, M. D., L. A. Crompton, J. A. Metcalfe, and J. France. 2001. Modelling mammary metabolism in the dairy cow to predict milk constituent yield, with emphasis on amino acid metabolism and milk protein production: Model construction. J. Theor. Biol. 213:223-239.

Hill, J., D. F. Chapman, J. L. Tharmaraj, J. Jacobs, and B. R. Cullen. 2014. Increasing home-grown forage consumption and profit in non-irrigated dairy systems. 3. Intake, milk production and composition, bodyweight and body condition score. Anim. Prod. Sci. $54: 247-255$.

IPCC. 2006. 2006 IPCC Guidelines for National Greenhouse Gas Inventories, Volume 4, Agriculture, Forestry and Other Land Use. Intergovernmental Panel on Climate Change IGES, Japan.

Jeffrey, S. J., J. O. Carter, K. M. Moodie, and A. R. Beswick. 2001. Using spatial interpolation to construct a comprehensive archive of Australian climate data. Environ. Model. Softw. 16:309-330.

Johnson, I. R. 2013. DairyMod and the SGS Pasture Model: A Mathematical Description of the Biophysical Model Structure. IMJ Consultants, Dorrigo, NSW, Australia.

Johnson, I. R., D. F. Chapman, V. O. Snow, R. J. Eckard, A. J. Parsons, M. G. Lambert, and B. R. Cullen. 2008. DairyMod and EcoMod: Biophysical pastoral simulation models for Australia and New Zealand. Aust. J. Exp. Agric. 48:621-631.

Johnson, I. R., J. France, J. H. M. Thornley, M. J. Bell, and R. J. Eckard. 2012. A generic model of growth, energy metabolism, and body composition for cattle and sheep. J. Anim. Sci. 90:4741-4751.

Johnson, I. R., G. M. Lodge, and R. E. White. 2003. The Sustainable Grazing Systems Pasture Model: Description, philosophy and application to the SGS National Experiment. Aust. J. Exp. Agric. 43:711-728.

Neal, H. D. StC., and J. H. M. Thornley. 1983. The lactation curve in cattle: A mathematical model of the mammary gland. J. Agric. Sci. 101:389-400.

NRC. 2001. Nutrient Requirements of Dairy Cattle. 7th ed. National Academy Press, Washington, DC. 
NRC. 2007. Nutrient Requirements of Small Ruminants. Sheep, Goats, Cervids, and New World Carnelids. National Academy Press, Washington, DC.

Olesen, J. E., K. Schelde, A. Weiske, M. R. Weisbjerg, W. A. H. Asman, and J. Djurhuus. 2006. Modelling greenhouse gas emissions from European conventional and organic dairy farms. Agric. Ecosyst. Environ. 112:207-220.

Oreskes, N., K. Shrader-Frechette, and K. Belitz. 1994. Verification, validation, and confirmation of numerical models in the earth sciences. Science 263:641-646.

Rattray, P. V., W. N. Garrett, N. E. East, and N. Hinman. 1974. Growth, development and composition of the ovine conceptus and mammary gland during pregnancy. J. Anim. Sci. 38:613-626.

Rook, A. J., J. France, and M. S. Dhanoa. 1993. On the mathematical description of lactation curves. J. Agric. Sci. Camb. 121:97-102.

Schils, R. L. M., M. H. A. de Haan, J. G. A. Hemmer, A. van den Polvan Dasselaar, J. A. de Boer, A. G. Evers, G. Holshof, J. C. van
Middelkoop, and R. L. G. Zom. 2007a. DairyWise, a whole-farm dairy model. J. Dairy Sci. 90:5334-5346.

Schils, R. L. M., J. E. Olesen, A. del Prado, and J. F. Soussana. 2007b. A review of farm level modelling approaches for mitigating greenhouse gas emissions from ruminant livestock systems. Livest. Sci. 112:240-251.

Tharmaraj, J. L., D. F. Chapman, J. Hill, J. Jacobs, and B. R. Cullen. 2014. Increasing home-grown forage consumption and profit in non-irrigated dairy systems. 2. Forage harvested. Anim. Prod. Sci. $54: 234-246$.

Thornley, J. H. M., and J. France. 2007. Mathematical Models in Agriculture. CAB International, Wallingford, UK.

Thornley, J. H. M., and I. R. Johnson. 2000. Plant and Crop Modelling. Blackburn Press, Caldwell, NJ.

Wood, P. D. P. 1967. Algebraic model of the lactation curve in cattle. Nature 216:164-165. 